\title{
Biodiesel Extraction from Chicken Fat and Its Effect on the Performance and Emission Characteristics of the Diesel Engine
}

\author{
V. Hariram †, J. Godwin John, Subramanyeswara Rao, S. K. Baji Babavali, S. Muni Lokesh, D. Tejeswar Reddy \\ and S. Seralathan \\ Hindustan Institute of Technology and Science, Padur, Chennai-603103, Tamil Nadu, India \\ †Corresponding author: V. Hariram; connect2hariram@gmail.com
}

Nat. Env. \& Poll. Tech.

Website: www.neptjournal.com

Received: 01-05-2021

Revised: 12-06-2021

Accepted: 01-07-2021

Key Words:

Biodiesel

Chicken fat

Emission

Performance

Transesterification

\section{ABSTRACT}

This study focuses on the conversion of chicken fat into chicken fat methyl ester (CFME) and its use in the diesel engine. Baseline fuel i.e., diesel and chicken fat biodiesel are the fuels tested to study their effect on the performance and emission characteristics of diesel engines. To enhance the performance and emission characteristics, ethanol up to $20 \%$ is added as an additive to the chicken fat biodiesel. The physiochemical properties revealed that the fuel blends properties are closer to the diesel fuel. The experimental investigations revealed that additive blended biodiesel enhanced the performance by reducing the brake-specific fuel consumption and increasing the brake thermal efficiency. Moreover, the emissions are considerably reduced by the additive blended chicken fat biodiesel. Therefore, chicken fat biodiesel can be considered as a substitute fuel to be used in the diesel engine without any modifications.

\section{INTRODUCTION}

The rise in the price of fossil fuels, global economy, environmental awareness, and strict enforcement of norms by the pollution control board are the reasons that the development of alternate fuels became important. The search for alternate fuel to the diesel engine has become a recent trend in the research due to the depletion of fossil fuel. Using alternate fuels as biofuel can significantly reduce the implications on the greenhouse gas effects in the environment. In the entire ecosystem, $\mathrm{CO}_{2}$ is viewed as a serious problem in terms of climate change. In the automobile sector, it is seen as a serious problem as emissions are to be controlled since fuel combustion causes heavy $\mathrm{CO}_{2}$ emissions.

The search for alternate fuel for diesel engines has intensified in recent years with the imminent depletion of fossil fuel in near future. Among the alternative fuel options, biodiesel is currently favored in the land and sea transportation sectors due to the modern biodiesel production technology, and the compatibility of use of biodiesel with existing compression ignition engines without any major modifications. Waste cooking oil is identified as an alternative resource due to its lower price compared with other fuel sources. Besides this, another widely available resource is animal fat oil. Especially, chicken fat oil can be considered for alternate fuel resource as it has the highest biodiesel potent.
Harsh et al. (2019) detailed the research conducted on reducing emissions through the use of additives in biodiesel. The addition of additives had significantly reduced the emissions in the diesel engine. Mehmet (2019) investigated the emission and performance of the diesel engine when the fuel was added with $15 \%$ proponal. The injection pressure was also varied to optimize performance parameters by reducing emission. The reduction in injection pressure improved fuel consumption. Also, there was a considerable reduction in the emission of smoke and oxides of nitrogen due to the addition of alcohol.

Kamel et al. (2019) conducted an experimental study on the emission and performance analysis of ternary waste cooking oil biodiesel-diesel-propanol blends. The results revealed that the addition of propanol to the diesel fuel reduced the emissions of carbon monoxide, oxides of nitrogen, and smoke besides reducing exhaust gas temperature. Deepak et al. (2020) presented the results of an experimental examination into the effects of metal-based additions in biodiesel blends. The chicken fat oil biodiesel was used as the fuel. The experiment was done under varied conditions and the results showed that the addition of the metal-based additives improved the performance of the engine and reduced the engine emissions. 
Dhanasekaran et al. (2019) discussed the utilization of waste cooking oil in a light-duty diesel engine to minimize emissions. The research was aimed to replace diesel with waste cooking oil by taking three blend ratios. Finally, the authors concluded that emissions gradually decreased with an increase in n-proponal addition for all the blends. Moreover, instead of treating it as a contaminated waste, the waste oil was put into good usage as fuel to achieve reduced emission. Vivian et al. (2016) investigated the effects of biodiesel made from swine and chicken fat residues on the diesel engine emissions like carbon monoxide, carbon dioxide, and nitrogen oxide. Biodiesel was produced from the chicken and swine fat wastage. It was observed that fuel consumption increased by up to $5 \%$, whereas engine emissions were observed to reduce drastically. This study showed the way that chicken and swine fat wastages can be used to producing biodiesel and its use in the diesel engine.

McCarthy et al. (2011) analyzed and compared the performance and emissions of an internal combustion engine fuelled with petroleum diesel and different biodiesels sourced from canola, palm, and beef tallow. Two different types of biodiesels were tested and analyzed with different blend ratios which showed a lower exhaust emission and better performance for Type ' $\mathrm{A}$ ' in comparison with Type ' $\mathrm{B}$ '. But the performance reported was not so high as compared with the reduction of two emissions namely, $\mathrm{CO}$ and $\mathrm{NO}_{\mathrm{x}}$. Mofijur et al. (2016) investigated the role of biofuel and its binary (diesel-biodiesel) and ternary (ethanol-biodieseldiesel) blend on reduction of emissions in internal combustion engines. Using up to $10 \%$ ethanol-25\% biodiesel in the petroleum-based diesel provided better results.

Ilker et al. (2017) experimented on the performance, emission, and combustion characteristics of a compression ignition engine using biofuel blends. Biodiesel and bioethanol were used for testing the performance of compression ignition engines. Using Bio-ethanol increased the brakespecific fuel consumption and volumetric efficiency. The combustion analysis was like the diesel fuel. Using bioethanol proved to reduce the emission like $\mathrm{HC}$ and smoke opacity. Ali Turkcan (2020) discussed the effects of different types of biodiesels and biodiesel-bioethanol-diesel blends on the cyclic variations and correlation coefficient. It was noted from the result that the fuel properties had much more effective due to the coefficient variation and correlation coefficient while comparing with the engine load.

Zaharin et al. (2017) investigated the influence of physicochemical features of biodiesel-alcohol fuel blends on diesel engine performance and emissions. Alcohol additives had good fuel properties that reduced viscosity and the presence of oxygen. This resulted in better engine combustion and improved the performance in terms of thermal efficiency which in turn reduced the engine emissions considerably. Hence, adding alcohol-based additives provided better results for biodiesel.

Based on these studies, it can be understood that biodiesel is a good alternative resource for diesel fuel. Also, using biodiesel leads to a significant reduction in $\mathrm{CO}_{2}$. The disposal of chicken waste is causing ecological problems. Moreover, chicken fat is a waste product that is used as a resource for biofuel production. Hence, the objective of this study is to evaluate the effect of adding an additive to the produced biodiesel from chicken fat which is used as fuel and to optimize the blend ratios in terms of performance and emission characteristics of the diesel engine.

\section{MATERIALS AND METHODS}

\section{Oil Extraction}

The source for bio-oil production is chicken fat. The chicken fat is collected from the slaughterhouse of the poultry farm. The chicken fat is then washed with water, later it is cleansed with de-ionized water. The fat is made free from the flesh and skin of the chicken. The free fatty acid content present is found to be $4.16 \%$ which is high, and hence it should be pretreated. Using the magnetic stirrer, the fat content is dissolved for 30 minutes by maintaining it at a temperature of $60^{\circ} \mathrm{C}$ upon considering the fat weight and molar to fat ratio of $20 \%$ of sulphuric acid as weighed at 40:1 ratio. This acid is added with the alcohol in a beaker $(250 \mathrm{~mL}$ capacity) and then it is poured into the fat-containing flask. Now, the mixture is taken into a water bath in which temperature is regulated at $60^{\circ} \mathrm{C}$ and the speed is kept at $150 \mathrm{rpm}$ for 80 minutes. When the process is over, the mixture is left in the

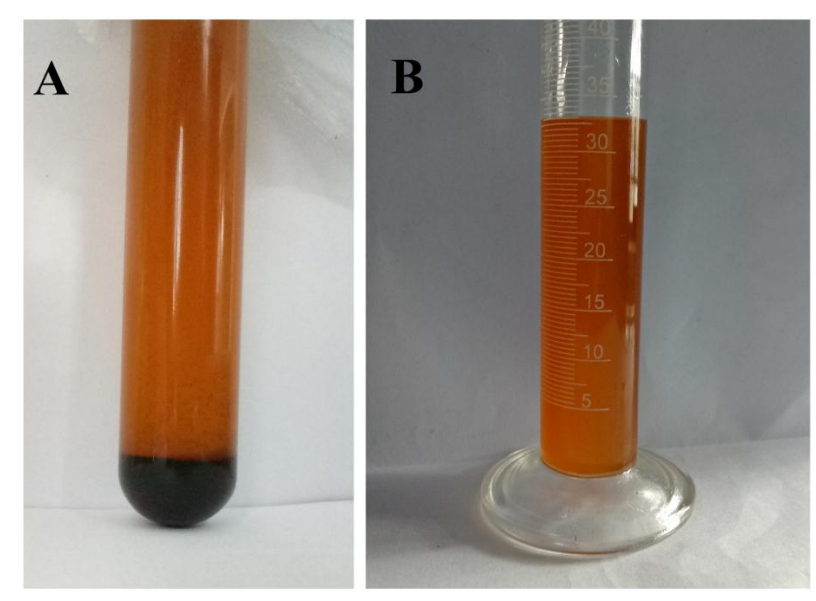

Fig. 1 (A) Chicken fat oil and its (B) biodiesel. 
Table 1: Comparison of properties of chicken fat methyl esters and diesel.

\begin{tabular}{|c|c|c|c|c|}
\hline Properties & CFME & Diesel & $\begin{array}{l}\text { ASTM } \\
\text { standards } \\
\text { for } \\
\text { Biodiesel }\end{array}$ & Method \\
\hline Density at $15^{\circ} \mathrm{C} \mathrm{kg} \cdot \mathrm{m}^{-3}$ & 870 & 830 & $860-900$ & D4052 \\
\hline $\begin{array}{l}\text { Kinematic Viscosity } \\
\text { at } 40^{\circ} \mathrm{C} \mathrm{mm}^{2} \cdot \mathrm{s}^{-1}\end{array}$ & 4.386 & 2.6 & $1.9-6$ & D445 \\
\hline $\begin{array}{l}\text { AV mg of } \mathrm{KOH} \cdot \mathrm{gm}^{-1} \\
\text { of oil }\end{array}$ & 0.16 & 0.35 & $<0.8$ & D664 \\
\hline Cloud point, ${ }^{\circ} \mathrm{C}$ & 0.8 & -8 & NA & $\mathrm{D} 2500$ \\
\hline $\begin{array}{l}\text { Iodine value, } \mathrm{G} \mathrm{I}_{2} / 100 \\
\mathrm{gm}\end{array}$ & 80 & NA & 115 & D1959 \\
\hline
\end{tabular}

separating funnel overnight to get settled. Later, three layers are observed in which the underneath layer is chicken fat (Godwin et al. 2017a). This pretreated fat is found to have $0.43 \%$ FFA content which can be taken care of with the transesterification process. The bio-oil content is shown in Fig. 1A.

\section{Transesterification}

To convert the fat into biodiesel, alkaline-based transesterification is carried out. The fat is mixed with the methanol using an Erlenmeyer flask. The reaction catalyst used is $\mathrm{NaOH}$. This reaction environment is maintained at $65^{\circ} \mathrm{C}, 400$ rpm agitating speed, and 120 minutes reaction period. This process yielded $95.2 \%$ converted biodiesel. The extracted biodiesel is shown in Fig. 1B.

\section{Fuel Properties}

The fuel properties are determined in the Fuels and Lubricant Testing Laboratory, Hindustan Institute of Technology and Science, Chennai. Based on the experimentation, the density of the chicken fat methyl ester (CFME) is found to be $870 \mathrm{~kg} \cdot \mathrm{m}^{-}{ }^{3}$, and kinematic viscosity is $4.386 \mathrm{~mm}^{2} . \mathrm{s}^{-1}$. The values of the diesel fuel and Chicken fat biodiesel are shown in Table 1.

\section{Test Fuel Formulation}

Ultrasonication is the method used to blend the fuel. The fuels blended are Diesel, Ethanol, and Diethyl ether. Ethanol is added with diesel because it has a high latent heat of vaporization. The globally accepted blend ratio is B20, hence this is used in this research work D80 CFB20 (80\% of conventional diesel and $20 \%$ of chicken fat biodiesel). In this experimental study $10 \%$ of ethanol is added to D80 CFB20 to enhance the performance of the engine (which is D80 CFB20 E10) and further to check its improvisation performance, $20 \%$ ethanol is added as the next fuel (which
Table 2: Specifications of the test engine.

\begin{tabular}{|ll|}
\hline Rated power $(\mathrm{kW})$ & 5.2 \\
Bore $(\mathrm{mm})$ & 87.50 \\
Stroke $(\mathrm{mm})$ & 110.00 \\
Compression ratio & $17.5: 1$ \\
Speed (rpm) & 1500 \\
Injection pressure (bar) & 210 \\
Injection timing & $23^{\circ} \mathrm{BTDC}$ \\
\hline
\end{tabular}

is D80 CFB20 E20). Based on the mixing capability and stability, the mass balance was achieved in these fuel blends. Considering the miscibility of ethanol additive with diesel - biodiesel blend, the fuel D80 CFB20 E10 was formulated as (Diesel $72.72 \%$, biodiesel 18.18\%, and ethanol 9.09\%) and similarly D80 CFB20E20 (Diesel 66.67\%, biodiesel $16.67 \%$, and ethanol $16.67 \%$ ) which helps to achieve the mass balance (Godwin et al. 2017b).

\section{Experimental Setup}

The experimentation is carried out in the Engine Testing Laboratory, Hindustan Institute of Technology and Science, Chennai. Direct injection water-cooled single-cylinder four-stroke constant speed compression ignition (CI) engine is used to determine the performance and emission characteristics. This engine is attached with an eddy current dynamometer which is water-cooled. The speed of the CI engine is kept constant at $1500 \mathrm{rpm}$. The engine is tested under stable state conditions and the engine setup is shown in Fig. $2 \mathrm{~A}$ and 2B. The technical features of the $\mathrm{CI}$ engine are listed in Table 2. The emission characteristics are measured using AVL444 gas analyzer and Bosch Smoke meter.

\section{RESULTS AND DISCUSSION}

This section explains the performance and emission characteristics of the test fuel, chicken fat methyl ester (CFME), and its blends used in the direct injection single cylinder compression ignition engine.

\section{Brake Specific Fuel Consumption}

Brake specific fuel consumption (BSFC) is the energy spent to produce useful power output, which is a measure of fuel efficiency of the CI engine. Fig. 3 represents the variations in BSFC with respect to brake mean effective pressure of diesel, D80 CFB20, D80 CFB20 E10 and D80 CFB20 E20 blends. For the highest engine load conditions, the data observed for the fuel blends D100, D80 CFB20, D80 CFB20 E10 and D80 CFB20 E20 are 0.24 kg.kWhr ${ }^{-1}, 0.28$ kg.kWhr ${ }^{-1}, 0.24$ kg.kWhr ${ }^{-1}$ and 0.25 kg.kWhr ${ }^{-1}$ respectively. 

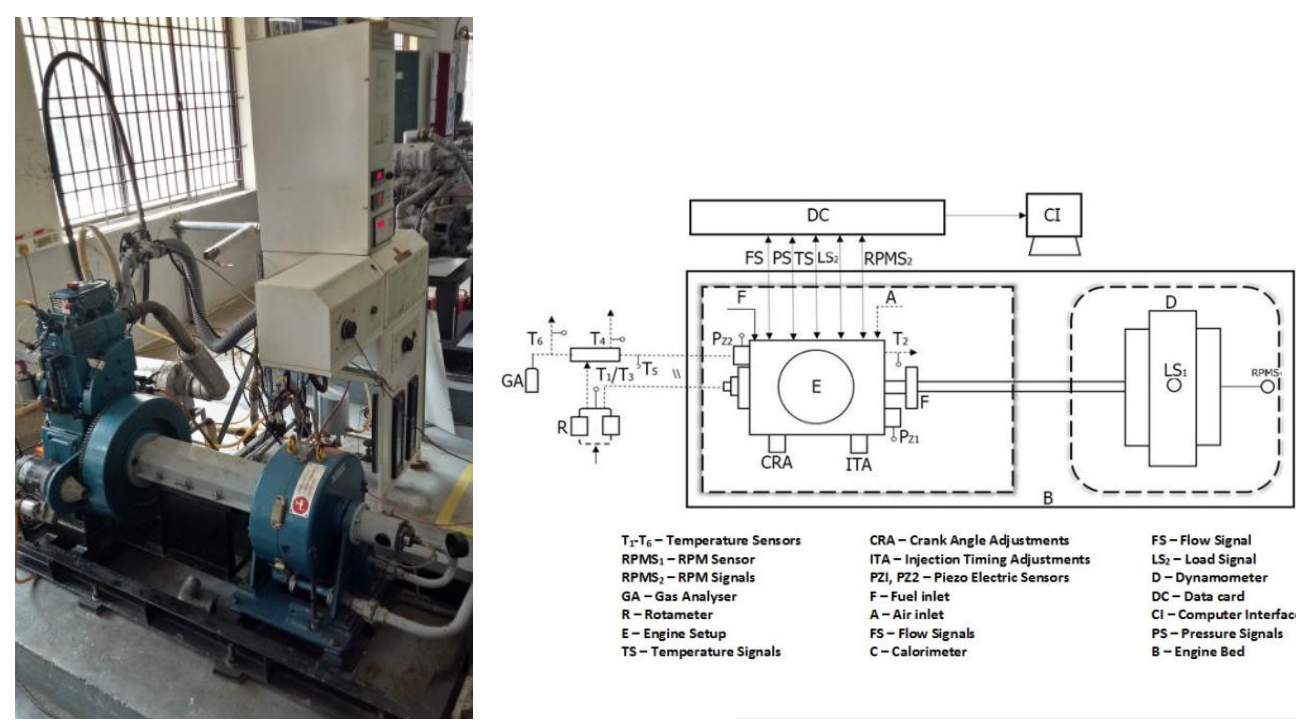

$T_{1}-T_{6}-$ Temperature Sensors RPMS - RPM Sensor
RPMS GA - Gas Analyser R-Rotameter E-Engine Setup TS - Temperature Signals
CRA - Crank Angle Adjustments ITA-Injection Timing Adjustments PZ1, PZ2 - Piezo Electric Sensors F-Fuel inlet A-Air inlet FS - Flow Signak C-Calorimeter
FS - Flow Signal LS $S_{2}$ - Load Signal D-Dynamometer DC - Data card $\mathrm{Cl}$-Computer Interface PS - Pressure Signals

Fig. 2: (A) Engine Testbed, (B) Schematic Setup.

As can be observed, the B20 blend consumed more fuel than other fuel blends. This may be due to higher viscosity and density resulting in improper mixture formation inside the cylinder. Assimilated additive in the blend boosted the combustion thereby lowering the fuel consumption which may be due to higher miscibility (Hariram et al. 2017). Comparing all the blends, D80 CFB20 E10 showed the lowest fuel consumption, and also it is nearly equivalent to diesel fuel.

\section{Brake Thermal Efficiency}

The ratio between brake power output and fuel power determines the thermal efficiency of the CI engine. The variations

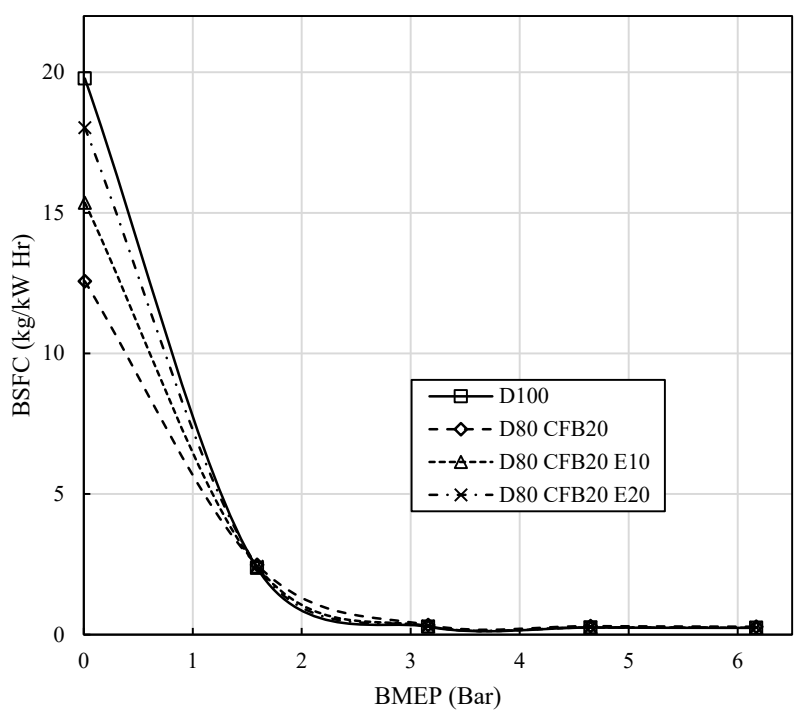

Fig. 3: Brake specific fuel consumption. of the brake thermal efficiency against brake mean effective pressure is detailed in Fig. 4.

Brake thermal efficiency of diesel fuel and its blends are $35.47 \%$ (D100), 33.03\% (D80 CFB20), 34.77\% (D80 CFB20 E10) and $37.8 \%$ (D80 CFB20 E20) at full load conditions. At low load conditions, the diesel fuel showcased a higher brake thermal efficiency. As the load is increased, the additive blend showcased the highest efficiency. This may be due to the availability of the excess amount of oxygen leading to proper combustion (Hariram et al. 2019). Surface tension between the CFME and diesel fuel (D80 CFB20) might be poor because of which the atomization became inferior leading to inferior performance of the CI engine.

\section{Unburned Hydrocarbon Emission}

Unburned hydrocarbon (UBHC) emission usually occurs due to improper combustion, deposits of carbon in crevice volume, and low temperatures. The variations of UBHC emission with BMEP are depicted in Fig. 5. The UBHC emissions for D100 and D80 CFB20 are found to be 36 ppm, and 35ppm, respectively at higher loads. The ethanol addition made the evaporation easier at increased cylinder temperature. This leads to better combustion and as can be seen in Fig. 5, at higher loads, the UBHC emission is lower compared to diesel fuel. As observed in Fig. 5, as the load increased, the UBHC emission is reduced due to better combustion.

\section{Carbon monoxide emission}

Improper combustion leads to $\mathrm{CO}$ emission. The variation in $\mathrm{CO}$ emissions with respect to BMEP at various load condi- 


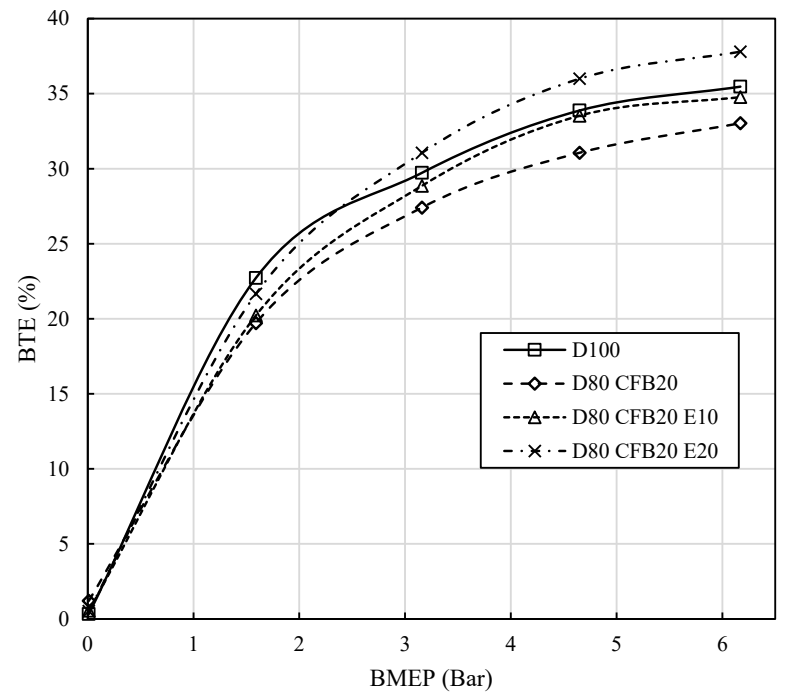

Fig. 4: Brake thermal efficiency.

tions is shown in Fig. 6. The values of the $\mathrm{CO}$ emissions as recorded in Fig. 6 are $0.112 \%$ (D100), 0.17\% (D80 CFB20), $0.083 \%$ (D80 CFB20 E10) and 0.073\% (D80 CFB20 E20) respectively. D80 CFB20 showcased a higher formation of $\mathrm{CO}$ which may be due to the higher density and viscosity of the biodiesel blend leading to incomplete combustion. A decrease in $\mathrm{CO}$ emission by supplementation of additive may be due to the complete combustion of the blend inside the chamber because of the reduced viscosity. This may be due to better atomization of the fuel resulting in complete combustion thereby reducing the $\mathrm{CO}$ formation.

\section{Oxides of Nitrogen Emission}

At elevated temperatures inside the combustion zone, nitrogen mixes with air to forms the oxides of nitrogen. The

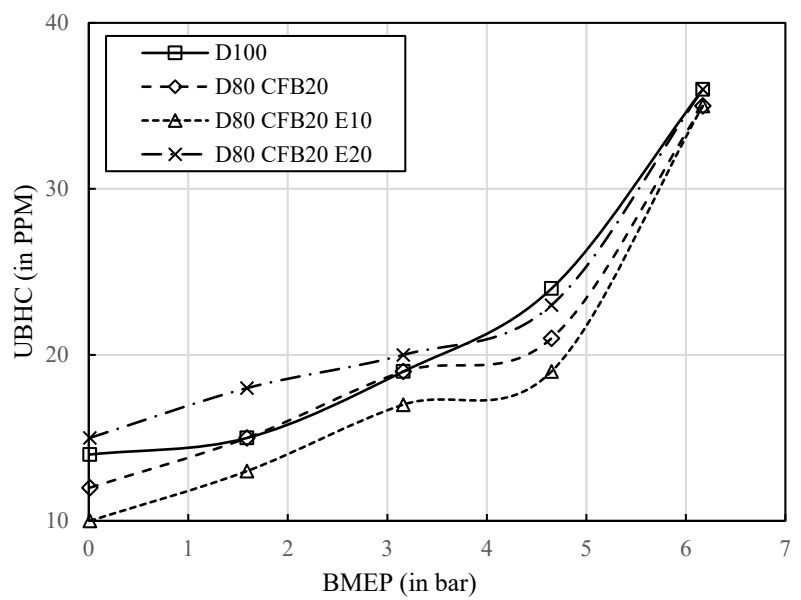

Fig. 5: Unburned hydrocarbon emission. variations in $\mathrm{NO}_{\mathrm{x}}$ emissions are detailed in Fig. 7. At full load conditions, the $\mathrm{NO}_{\mathrm{x}}$ emissions released by the fuels D100, D80 CFB20, D80 CFB20 E10, and D80 CFB20 E20 are 1744 ppm, 1685 ppm, 1688 ppm, and 1741 ppm, respectively. All the biodiesel blends showed lower values in comparison with diesel fuel which means that the biodiesel fuel is better with respect to $\mathrm{NO}_{\mathrm{x}}$ emissions. The highest value of $\mathrm{NO}_{\mathrm{x}}$ emissions among biodiesel blends is reported for the D80 CFB20 E20 fuel blend. This may be due to the additional oxygen content and reduced viscosity which improved the combustion behavior thereby increasing the temperature inside the chamber wherein the Zeldovich Mechanism give rise to the increased level of $\mathrm{NO}_{\mathrm{x}}$ emissions.

\section{Smoke Emission}

Figure 8 shows the variations of smoke opacity levels with respect to BMEP. It is observed that fuels D100, D80 CFB20, D80 CFB20 E10 and D80 CFB20 E20 showed the

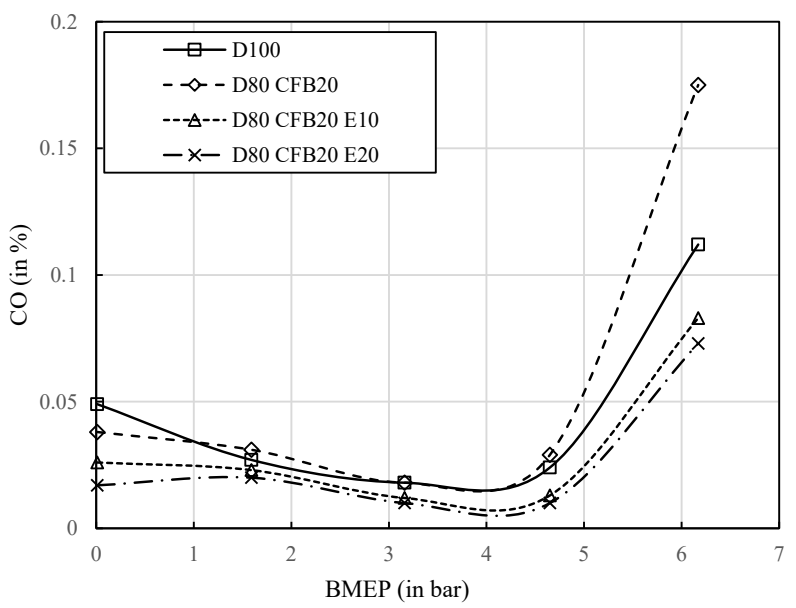

Fig. 6: Carbon Monoxide Emission.

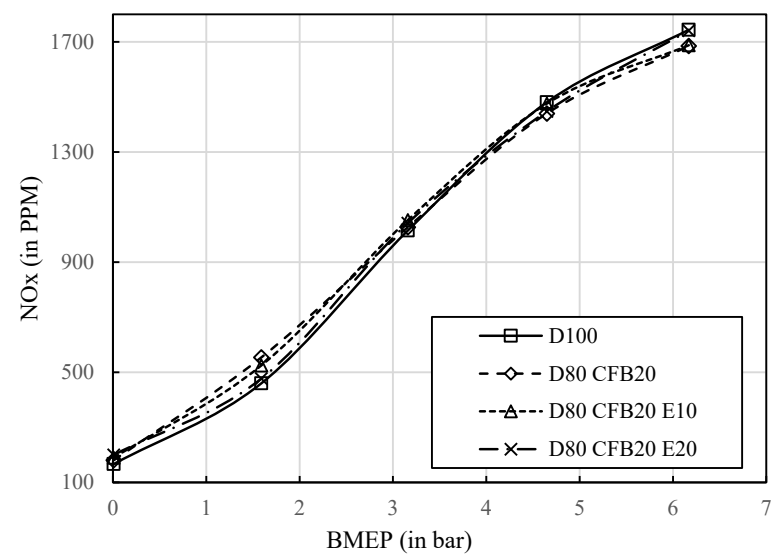

Fig. 7: Oxides of Nitrogen Emission. 
smoke opacity values as $61.83 \%, 64.8 \%, 57.3 \%$ and $57.8 \%$ respectively at full load conditions. As can be observed, the diesel and D80 CFB20 blend give higher smoke opacity values than the additive added fuel blends. The reduced smoke formation of the biodiesel blends with additive may be due to the availability of surplus oxygen content at an increased temperature which oxidizes the carbon matter thereby preventing it from getting deposited in the chamber.

\section{Carbon Dioxide Emission}

Fig. 9 details the carbon dioxide emission variations with BMEP at all loads for the fuels D100, D80 CFB20, D80 CFB20 E10 and D80 CFB20 E20. As the load is increased, $\mathrm{CO}_{2}$ emissions also increased. $\mathrm{CO}_{2}$ emission values are reduced for the biodiesel blends. This is due to the availability of the oxygen content. Also, it can be noted that the results of carbon dioxide emissions at full load condition are $8.85 \%$, $8.8 \%, 8.49 \%$ and $8.45 \%$ for fuels D100, D80 CFB20, D80 CFB20 E10 and D80 CFB20 E20 respectively. Due to oxygen content availability, $\mathrm{CO}$ is converted into $\mathrm{CO}_{2}$. Moreover, the conversion of $\mathrm{CO}$ to $\mathrm{CO}_{2}$ is better than the toxic $\mathrm{CO}$ emissions coming out as engine emissions. The released carbon dioxide can be considered as an environment-friendly aspect rather than releasing $\mathrm{CO}$ emissions to the environment as globally it is known that ground-level $\mathrm{CO}_{2}$ is manageable.

\section{CONCLUSION}

Experimental investigations on the use of chicken fat methyl ester (CFME) and, its blends in the diesel engine are analyzed in terms of performance and emission characteristics. The chicken fat methyl ester is extracted from the waste chicken fat. The performance of the diesel engine is

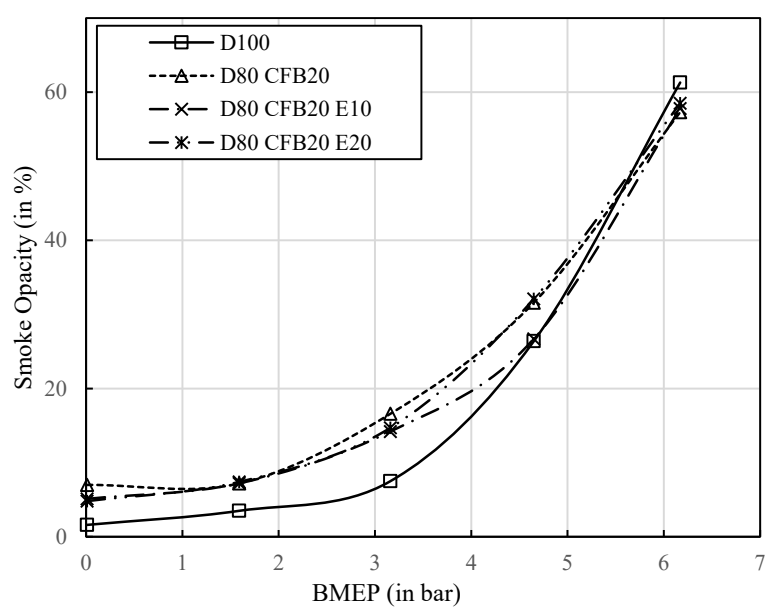

Fig. 8: Smoke Emission. evaluated in terms of brake-specific fuel consumption and brake thermal efficiency, whereas the emission parameters are evaluated through $\mathrm{UBHC}, \mathrm{CO}, \mathrm{NO}_{\mathrm{x}}$, Smoke, and $\mathrm{CO}_{2}$ emission values. Additive-based fuel blend, D80 CFB20 E10 recorded the lowest fuel consumption while D80 CFB20 E20 reported the highest brake thermal efficiency. D80 CFB20 E10 showcased the lowest HC emission throughout different loading conditions whereas the lowest $\mathrm{CO}$ emission is given by the D 80 CFB20 E20 blend. Among all the tested biodiesel blends, the highest emission values of oxides of nitrogen are released by the D80 CFB20 E20 blend. D80 CFB20 E10 fuel blend showed the lowest smoke emission. Based on the data obtained, it can be concluded that chicken fat biodiesel can be used as a substitute fuel in the CI engine without any modification in the engine. Moreover, adding the additive to this biodiesel further increases the performance and controls the emission levels of the diesel engine.

\section{REFERENCES}

Ali Turkcan, M. 2020. The effects of different types of biodiesels and biodiesel-bioethanol-diesel blends on the cyclic variations and correlation coefficient. Fuel, 261: 116453.

Deepak, K.T., Manjunatha, T.K.S. and Ramesha, D.K. 2020. Experimental investigation on the influence of metal-based additives on diesel engines along with biodiesel blends. Mater. Today: Proceedings, 38(1): 407-412.

Dhanasekaran, R., Ganesan, S., Rajesh Kumar, B. and Saravanan, S. 2019. Utilization of waste cooking oil in a light-duty DI diesel engine for cleaner emissions using bio-derived propanol. Fuel, 235: 832-837.

Godwin, J.J., Hariram, V., Seralathan, S. and Jaganathan, R. 2017a. Effect of oxygenating on emission and performance parameters of a CI engine fuelled with blends of diesel-algal biodiesel. Int. J. Renew. Energy Res., 7(4): 2041-2047.

Godwin, J.J., Hariram, V. and Seralathan, S. 2017b. Emission reduction using improved fuel properties of algal biodiesel and its blends. Energy Sour. A: Recov. Util. Environ. Eff., 40(1): 45-53.

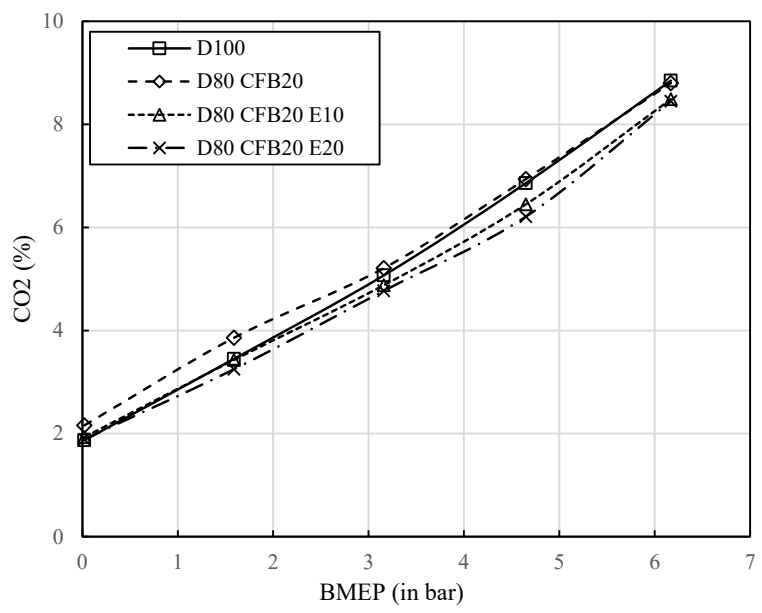

Fig. 9: Carbon dioxide emission. 
Harsh, K., Hardik, B., Yuvrajsinh, D. and Sajan, C. 2019. Investigation of emulsion and effect on emission in CI engine by using diesel and bio-diesel fuel: A review. Egypt. J. Pet., 28: 323-337.

Hariram, V., Godwin, J.J. and Seralathan, S. 2017. Cottonseed biodiesel as alternative fuel: Production and its characterization analysis using spectroscopic studies. Int. J. Renew. Energy Res., 7(3): 1333-1339.

Hariram, V., Godwin, J.J. and Seralathan, S. 2019. Impact of oxygenated cotton seed biodiesel on combustion, performance, and emission parameters in a direct injection CI engine. International Journal of Ambient Energy, 40 (2): 158-169.

Ilker, O., Ali, K. and Murat, C. 2017. Performance, emission, and combustion analysis of a compression ignition engine using biofuel blends. Thermal Sci., 21(1B): 511-522.

Kamel, B., Atabani, A.E., Sutha, S., Mohammed, M.N., Gediz, U., Orhan, A., Gopalakrishnan, K., Abdulkadir, A. and Awais, B. 2019. Fuels properties, characterizations, and engine and emission performance analyses of ternary waste cooking oil biodiesel-diesel-propanol blends. Sustain. Energy Technol. Assess., 35: 321-334.
McCarthy, P., Rasul, M.G. and Moazzem, S. 2011. Analysis and comparison of performance and emissions of an internal combustion engine fuelled with petroleum diesel and different bio-diesels. Fuel, 90: 2147-2157.

Mehmet, S. 2019. The effect of the injection pressure on a single cylinder diesel engine fueled with propanol-diesel blend. Fuel, 254: 115617.

Mofijur, M., Rasul, M.G., Hyde, J., Azad, A.K., Mamat, R. and Bhuiya, M.M.K. 2016. Role of biofuel and their binary (diesel-biodiesel) and ternary (ethanol-biodiesel-diesel) blends on internal combustion engines emission reduction. Renewable and Sustain. Energy Rev., 53: 265-278.

Vivian, F., Anildo, C., Marina, C., De, P., Marcio, L., Busi, D.S., Rodrigo, D.S.N., Martha, M.H., Arlei, C. and Paulo, G.D.A. 2017. Effects of biodiesel made from swine and chicken fat residues on carbon monoxide, carbon dioxide, and nitrogen oxide emissions. J. Air Waste Manag. Assoc., 67(7): 754-762.

Zaharin, M.S.M., Abdullah, N.R., Najafi, G., Sharudin, H. and Yusaf, T. 2017. Effects of physicochemical properties of biodiesel fuel blends with alcohol $\mathrm{n}$ diesel engine performance and exhaust emissions: A review. Renew. Sustain. Energy Rev., 79: 475-493. 